\title{
DESIGN AND TESTING OF AN ADJUSTABLE BRAKING SYSTEM FOR AN FSAE VEHICLE
}

\author{
Ardashir Bulsara' ${ }^{1}$, Dhruvil Lakhani ${ }^{2}$, Yash Agarwal $^{3}$, Yash Agiwal $^{4}$ \\ ${ }^{I}$ Mechanical Department, Dwarkadas J.Sanghvi College of Engineering, Maharashtra, India \\ ${ }^{2}$ Mechanical Department, Dwarkadas J.Sanghvi College of Engineering, Maharashtra, India \\ ${ }^{3}$ Mechanical Department, Dwarkadas J.Sanghvi College of Engineering, Maharashtra, India \\ ${ }^{4}$ Mechanical Department, Dwarkadas J.Sanghvi College of Engineering, Maharashtra, India
}

\begin{abstract}
A Formula SAE racecar is supposed to have high performance and be light in weight at the same time. For the vehicle to perform well in a race it has to accelerate and decelerate as fast as possible. The braking system must be effectively designed for it to make the maximum use of the tires and take into account changes in weight distribution of the vehicle. A braking system must be versatile enough to adapt to different road conditions such as wet weather. Another key aspect which is incorporated is the frontrear split which is controlled by a balance bar that is easy to use and can change the braking characteristics on track.
\end{abstract}

Keywords: Pressure distribution, Manufacturing ease, Adjustable, Testing

\section{INTRODUCTION}

Formula SAE is an inter-collegiate design competition organized by the Society of Automotive Engineers (SAE) in which student engineers design, build, test and race an open wheeled formula style race car. Since the competitions inception in 1981, the cars have been evolving and changing and there has been no single design that stands out as "the best". The cars are designed to be light, safe, fast and very agile as the tracks are designed to run on have a very high frequency and range of corners, so slowing down quicker is as important as accelerating faster.

\section{OBJECTIVE}

To design and fabricate a brake system comprising of an adjustable pedal box and deceleration up to $1.65 \mathrm{G}$ which should be able to lock all 4 wheels at the same time, hence using maximum available traction, in a straight line and validate the calculations using two brake pressure sensors.

\section{METHODOLOGY}

The aim was to lock all the 4 wheels at the same time in a lightweight car using a 50-50 front rear bias, 1D simulations were carried out resulting in $1.6 \mathrm{~g}$ deceleration and the master cylinder and callipers were short listed. Since, this being a formula style race car, adjustability of pedal box was given highest importance so that it can fit any driver and giving them a good ergonomic feel about the car. The callipers were sourced from Sweden ISR and master cylinders from AP RACING. The Pedals are machined out of $\mathrm{Al} 6061$ and designed such that they are wide and tall for ergonomic considerations. Two brake pressure sensors were used to validate the calculations.

An important consideration in designing the system was the method of adjusting the bias forward and back by a small amount to account for the fact that the system should be versatile in its functioning i.e. it should work well in both dry and wet conditions. Hence the decision was taken to have independent front-rear circuits rather than the conventional diagonal split system.

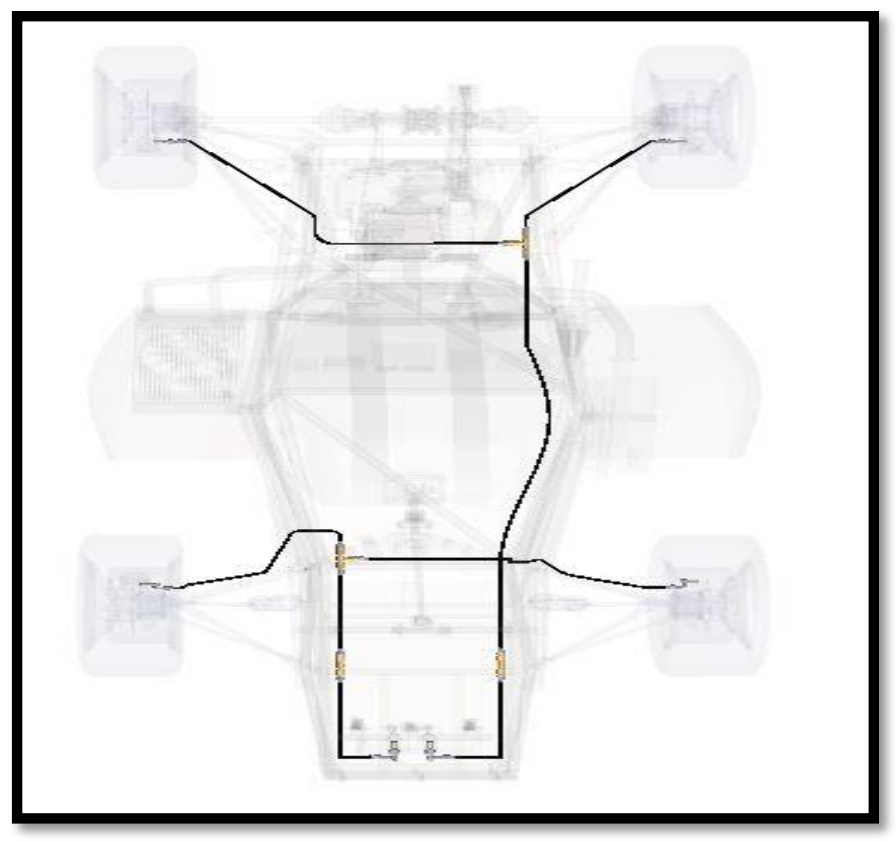

Fig -1: Front-rear split layout (with sensors in each closed system)

\section{PEDAL BOX DESIGN}

A floor mounted pedal assembly was selected since it helps keep the car height low and thus the center of gravity of the car would be as low as possible. The pedal assembly in this racecar consists of the Accelerator pedal, Brake pedal and the Clutch pedal. The brake pedal is constrained by the 
master cylinders and balance bar. The orientation of the brake pedal will therefore follow the orientation of the accelerator and the clutch pedal. The master cylinders return the brake pedal to its resting position. Thus, the other two pedals need a spring to return to their original position.

Basic force calculations were carried out. This can be explained by a Free Body Diagram of the transmission of pedal forces as shown.

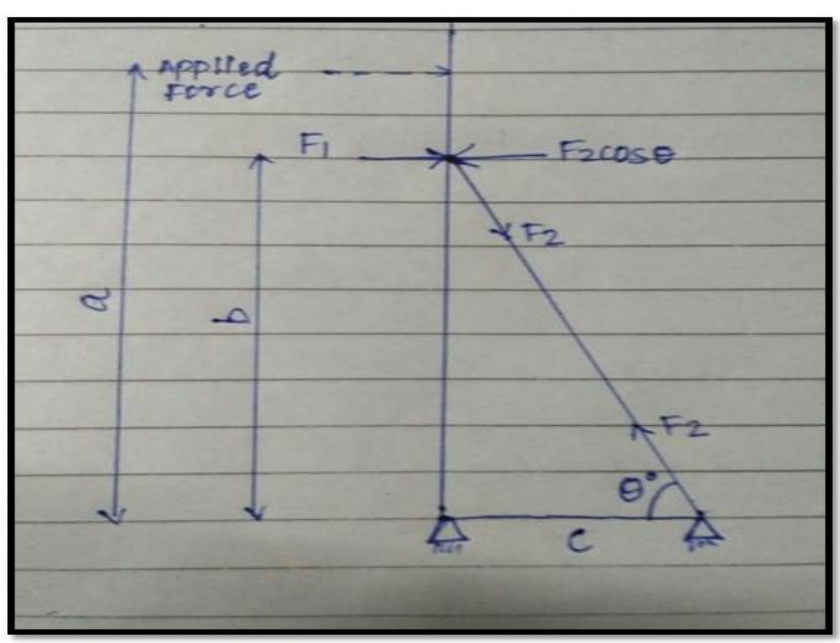

Fig -2: Free body diagram of the brake pedal

For the pedal to be in equilibrium,

$$
\mathrm{F} 1=\mathrm{F} 2 * \cos (\theta)
$$

Thus,

$$
\mathrm{F} 2=\mathrm{F} 1 / \cos (\theta)
$$

The angle $\theta$ needed to be larger so that its cosine value can be smaller, which will in return provide a larger advantage to multiply the applied force on the brake pedal without further increasing pedal height. The master cylinder angle was chosen as 70 degrees from the horizontal after iterative 1D simulations to achieve a high enough force multiple at the master cylinders .

After selection of the MCs, we designed all three pedals to have the same height and withstand appropriate forces which are applied to them in race conditions. Another aspect taken into consideration was the cost element of manufacturing, hence we selected waterjet cutting and designed the pedals accordingly using AL 6061-T6 as the material.

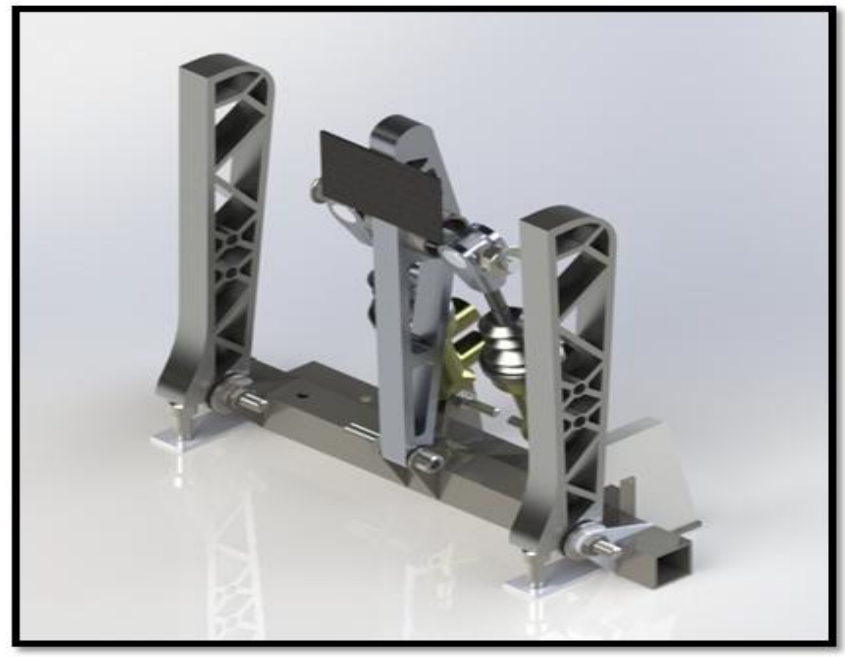

Fig -3: Pedal box assembly

\section{ROTOR}

In this calculation it was assumed that each rotor would share evenly in the overall heat transfer. This is not the actual case, however for the purpose of comparison this method was utilized.

In the end, Materials with the lowest temperature change were favoured as these materials would increase in temperature the least during braking.

Kinetic Energy of the Vehicle = Heat Energy Generated .

Thus,

$$
0.5 * \mathrm{M}^{*} \mathrm{v}^{\wedge} 2=\mathrm{m} * \mathrm{Cp} * \mathrm{dT} * \mathrm{n}
$$

Where, $\mathrm{M}=$ Mass of the Car, $\mathrm{v}=$ velocity of the car, $\mathrm{m}=$ Mass of the rotor, $\mathrm{Cp}=$ specific heat of the material, $\mathrm{dT}=$ change in temperature, $\mathrm{n}=$ Number of rotors.

Thus, considering $\mathrm{M}=250 \mathrm{~kg}, \mathrm{v}=23 \mathrm{~m} / \mathrm{s}, \mathrm{n}=4$, $0.5^{*} 250 * 23^{\wedge} 2=\mathrm{m} * \mathrm{Cp} * \mathrm{dT} * 4$

$66125 / * 4=\mathrm{m} * \mathrm{Cp} * \mathrm{dT}$

Thus, dT $=16531 \mathrm{~J} /\left(\mathrm{m}^{*} \mathrm{Cp}\right)$

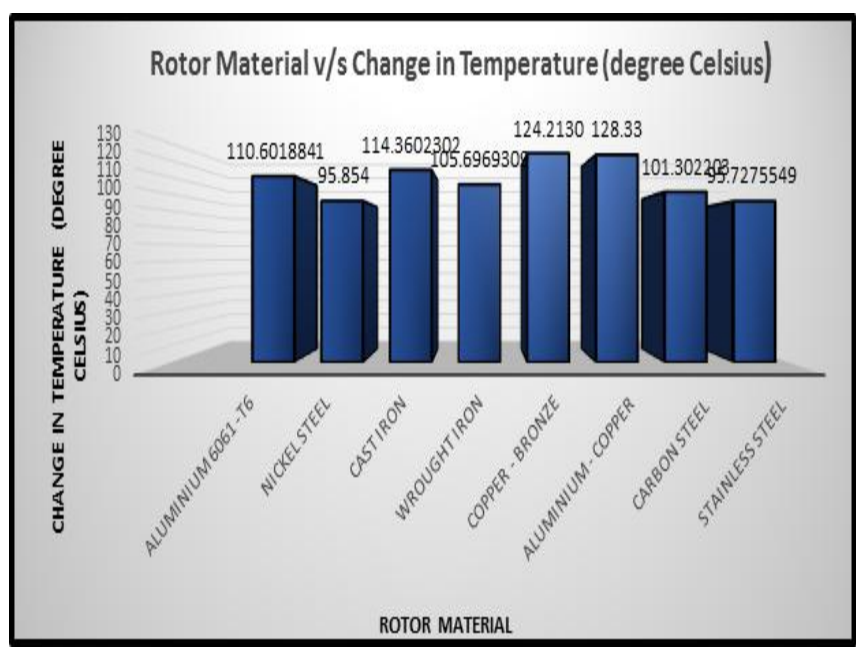

Fig -4: Rotor Material comparison chart 
Now, by putting different values of $\mathrm{Cp}$ for respective materials, the change in temperature for each of them can be found out.

The following graph shows temperature change of various materials depending on the above equation. Materials with the lowest temperature change were favored as these materials would increase in temperature the least during braking.

In most rotor designs there are cuts or holes in the surface where the rotor comes in contact with the brake pad. The main intention of these cuts is to reduce brake fade during braking. As the temperature of the brake pad begins reaching its design limit a faint layer of gas from the deterioration of the brake pad forms between the pad and the rotor. The effect of this gas layer is a severe decrease in the brake pad coefficient of friction, which translates as an ineffective brake to the driver. Also, when the heat generated is beyond the capacity of the rotor, it would result in failure of braking system as no more kinetic energy can be absorbed by it anymore.

Having cuts or holes in the rotor creates a vent or fan like effect, which flushes out this gas layer that forms. Two side effects of having these cuts in the rotor are reduced mass and an increase in the cooling ( since the surface area to allow for convection is higher.

This rotor caliper combination is designed to package within a 10 "' diameter wheel shell. It is mounted to the wheel hub directly in a semi-floating configuration, eliminating the need for a rotor carrier in between.

The thickness of the rotor is $4 \mathrm{~mm}$ since it is the least value matching the caliper specifications while also satisfying heat absorption requirements.

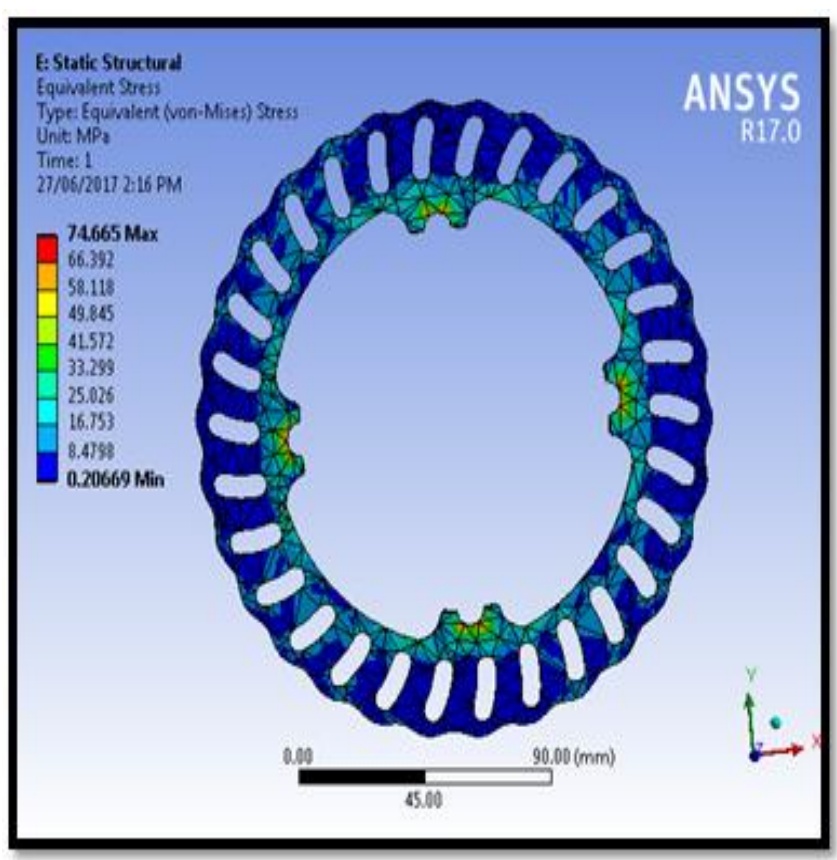

Fig -5: Static structural analysis of rotor

\section{FORCE DISTRIBUTION CALCULATIONS}

We started off with inputting the characteristics of the car like weight, wheelbase, cg position and deceleration value. this got us the values of weight transferred to the front wheels and through this data we could get the required torque values on each wheel.

\begin{tabular}{|c|c|c|c|c|}
\hline \multicolumn{5}{|c|}{ WEIGHT TRANSFER CHARACTERISTICS } \\
\hline \multicolumn{2}{|l|}{ STATIC VALUES } & \multicolumn{3}{|c|}{ DYNAMIC VALUES: (DRY CONDITIONS) } \\
\hline OVERALL WEIGHT(kg) & 250 & CG (AHEAD OF REAR)(MM) & 1150.88 & \\
\hline WHEELBASE (mm) & 1550 & CG (BEHIND OF FRONT)(MM) & 399.125 & \\
\hline CG (height) & 254 & Weight on Front Tyres & 180.097 & $72.039 \%$ \\
\hline weight on front $(\mathrm{kg})$ & $112.545 \%$ & Weight on Rear Tyres & 69.9032 & $27.961 \%$ \\
\hline weight on rear(kg) & $137.555 \%$ & & & \\
\hline rate of decelration(g) & 1.65 & & & \\
\hline COEFFICIENT OF FRICTION & 0.75 (DRY T) & RES) & & \\
\hline WHEEL DIA(INCH) & $18457 r$ & & & \\
\hline
\end{tabular}

Fig -6: Weight Transfer Characteristics

\begin{tabular}{|c|c|}
\hline \multicolumn{2}{|c|}{ REQUIRED TORQUE } \\
\hline FORCE FRONT AXLE & $2912.2 \mathrm{~N}$ \\
\hline FORCE REAR AXLE & $1130.3 \mathrm{~N}$ \\
\hline FORCE ON FRONT TIRE & $1456.1 \mathrm{~N}$ \\
\hline FORCE ON REAR TIRE & $565.17 \mathrm{~N}$ \\
\hline STOPPING FORCE FRONT & $1092.1 \mathrm{~N}$ \\
\hline STOPPING FORCE REAR & $423.88 \mathrm{~N}$ \\
\hline TORQUE REQUIRED FRONT & $249645 \mathrm{~N}-\mathrm{mm}$ \\
\hline TORQUE REQUIRED REAR & $96898 \mathrm{~N}-\mathrm{mm}$ \\
\hline
\end{tabular}

Fig -7: Required Torque

Next step was to calculate the braking torque per wheel which has to be in tune with the above values of required torque, or else the vehicle might lose control in panic braking scenarios, or give rise to massive over/understeer while entering a corner.

\begin{tabular}{|c|c|c|c|}
\hline \multicolumn{4}{|c|}{ BRAKES CALCS } \\
\hline PEDAL FORCE(lbs, kg, N) & 105 & 47.727 & $468.205(\mathrm{~N})$ \\
\hline PEDAL RATIO & 3.784 & & \\
\hline COEFFIECIENT OF FRICTION & 0.4 & & \\
\hline EFFECTIVE ROTOR DIA & 157 & $\mathrm{~mm}$ & \\
\hline \multicolumn{3}{|c|}{ FRONT CALLIPER (AREA) $\left(\mathrm{mm}^{\wedge} 2\right)$} & $1963.5 \mathrm{~mm}^{\wedge} 2$ \\
\hline NO. OF PISTONS & 4 & & \\
\hline DIA OF PISTONS (mm) & 25 & & \\
\hline \multicolumn{3}{|l|}{ REAR CALLIPER(AREA) $\left(\mathrm{mm}^{\wedge} 2\right)$} & $981.748 \mathrm{~mm}^{\wedge} 2$ \\
\hline NO. OF PISTONS & 2 & & \\
\hline DIA OF PISTONS & 25 & & \\
\hline FRONT MASTER CYLINDER (in & 0.625 & 15.875 & $197.933 \mathrm{~mm}^{\wedge} 2$ \\
\hline REAR MASTER CYLINDER (incl & 0.7 & 17.78 & $248.287 \mathrm{~mm}^{\wedge} 2$ \\
\hline \multirow[t]{2}{*}{ BALANCE BAR BIAS } & \multicolumn{3}{|c|}{$50 \%$ front } \\
\hline & \multicolumn{3}{|c|}{$50 \%$ rear } \\
\hline
\end{tabular}

Fig -8: Brake Calculation part 1 
INCLINATION OF MC (DEGREE)

FORCE ON FRONT MASTER CYLINDER

FORCE ON REAR MASTER CYLINDER

PRESSURE ON FRONT LINES

PRESSURE ON REAR LINES

FRONT CLAMPING FORCE / calliper

REAR CLAMPING FORCE / calliper

FRONT STOPPING FORCE (DRY)

REAR STOPPING FORCE (DRY)

FRONT BRAKING TORQUE (DRY)

REAR BRAKING TORQUE (DRY)

Fig -9: Brake Calculation Part 2

There were many iterations performed to match the required and acheived torque vales on each wheel and it resulted in the conclusion as shown in fig below.

\begin{tabular}{|c|c|c|c|}
\hline & NCLUSIO & & \\
\hline & FRONT & REAR & Units \\
\hline Split & $50 \%$ & $50 \%$ & \\
\hline Force on master cylinder & 885.836 & 885.836 & $\mathrm{~N}$ \\
\hline Master Cylinder Area & 197.933 & 248.287 & $\mathrm{~mm}^{\wedge} 2$ \\
\hline Line pressure & 4.47544 & 3.56779 & $\mathrm{~N} / \mathrm{mm}^{\wedge} 2$ \\
\hline & 649.109 & 517.466 & psi \\
\hline & 4475442 & 3567795 & Pascal \\
\hline & 44.7544 & 35.6779 & bar \\
\hline Calliper piston area & 1963.5 & 981.748 & $\mathrm{~mm}^{\wedge} 2$ \\
\hline Clamping force (one calliper) & 8787.51 & 3502.67 & $\mathrm{~N}$ \\
\hline Stopping force on one disc & 3515 & 1401.07 & $\mathrm{~N}$ \\
\hline Braking torque per disc & 275928 & 109984 & $\mathrm{~N}-\mathrm{mm}$ \\
\hline Required braking torque & 249645 & 96898 & $\mathrm{~N}-\mathrm{mm}$ \\
\hline DISTRIBUTION OF TORQUE & 71.5002 & 28.4998 & $\%$ \\
\hline DISTRIBUTION OF WEIGHT & 72.0387 & 27.9613 & $\%$ \\
\hline
\end{tabular}

Fig -10: Brake Calculation conclusion

\section{VALIDATION OF LINE PRESSURE}

The oem parts were sourced from the respective manufacturers and then assembled.The pedal frame and pedals themselves are easy to manufacture and not time consuming. The entire system was finally assembled and now ready to test. Two brake pressure sensors were bought and assembled mid-line in the front and rear systems.

Physical tests were carried out by applying a certain known force on the brake pedal as the driver would apply with the help of a pre calibrated spring balance and the pressure output from the two sensors front and rear were noted and compared with the calculations done beforehand. This was done for two configurations i.e. 50-50 bias and 45-55 bias front to rear, which would be typically used while performing in wet conditions.
Initially, the balance bar was set at 50:50 bias and a load of $20 \mathrm{~kg}$ was applied with the spring balance. For $20 \mathrm{~kg}$ force, the Brake Pressure values in front and rear lines are as follows:-

Table -1: Observation table for 20kg load and 50-50bias

\begin{tabular}{|l|l|l|}
\hline Iteration No. & $\begin{array}{l}\text { Brake Pressure } \\
\text { Front (bar) }\end{array}$ & $\begin{array}{l}\text { Brake Pressure } \\
\text { Rear (bar) }\end{array}$ \\
\hline 1 & 17.55 & 14.13 \\
\hline 2 & 17.1 & 14.11 \\
\hline 3 & 16.98 & 14.71 \\
\hline 4 & 16.95 & 14.59 \\
\hline 5 & 17.82 & 13.85 \\
\hline 6 & 17.43 & 15.08 \\
\hline 7 & 17.28 & 14.18 \\
\hline Mean & $\mathbf{1 7 . 2 1}$ & $\mathbf{1 4 . 3 1}$ \\
\hline
\end{tabular}

Thus, for $20 \mathrm{~kg}$ force at 50:50 Brake Bias,

\begin{tabular}{|l|l|}
\hline $\begin{array}{l}\text { Brake Pressure Front } \\
\text { [observed] }: 17.21\end{array}$ & $\begin{array}{l}\text { Brake Pressure Front } \\
\text { [calculated] : 18.11 bar }\end{array}$ \\
\hline $\begin{array}{l}\text { Brake Pressure Rear } \\
\text { [observed] }: 14.31 \text { bar }\end{array}$ & $\begin{array}{l}\text { Brake Pressure Rear } \\
\text { [calculated] : 14.44 bar }\end{array}$ \\
\hline
\end{tabular}

The same was checked with $30 \mathrm{~kg}$ force at the spring balance. The pressure values recorded were as follows:-

\begin{tabular}{|l|l|}
\hline $\begin{array}{l}\text { Brake Pressure Front } \\
\text { [observed] }: 26.32\end{array}$ & $\begin{array}{l}\text { Brake Pressure Front } \\
\text { [calculated] }: 27.17 \text { bar }\end{array}$ \\
\hline $\begin{array}{l}\text { Brake Pressure Rear } \\
\text { [observed] }: 21.77 \text { bar }\end{array}$ & $\begin{array}{l}\text { Brake Pressure Rear } \\
\text { [calculated] }: 21.66 \text { bar }\end{array}$ \\
\hline
\end{tabular}

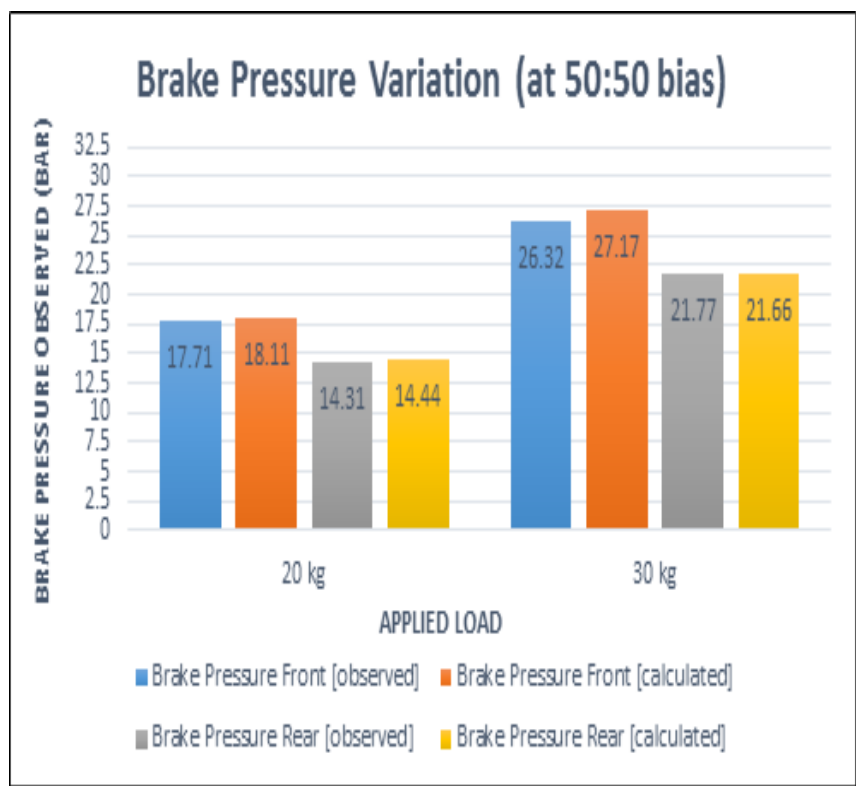

Fig -11: Summary of test performed at 50-50 bias

Now, the bias was changed to $55 \%$ in Front and $45 \%$ in Rear system. Again, a load of $20 \mathbf{~ k g}$ was applied and the brake pressure values were checked. The readings shown were as follows: 
Table -2: Observation table for 20kg load and 55-45bias

\begin{tabular}{|l|l|l|}
\hline Iteration No. & $\begin{array}{l}\text { Brake Pressure } \\
\text { Front (bar) }\end{array}$ & $\begin{array}{l}\text { Brake Pressure } \\
\text { Rear (bar) }\end{array}$ \\
\hline 1 & 18.85 & 12.97 \\
\hline 2 & 18.82 & 12.77 \\
\hline 3 & 18.22 & 12.8 \\
\hline 4 & 17.95 & 12.69 \\
\hline 5 & 17.9 & 13.1 \\
\hline 6 & 18.52 & 12.42 \\
\hline 7 & 18.36 & 12.81 \\
\hline Mean & $\mathbf{1 8 . 5 8}$ & $\mathbf{1 2 . 8 4}$ \\
\hline
\end{tabular}

Thus, for $20 \mathrm{~kg}$ force at 55:45 Brake Bias,

\begin{tabular}{|lc|lc|}
\hline $\begin{array}{l}\text { Brake Pressure } \\
\text { [observed] }: 18.58\end{array}$ & Front & $\begin{array}{l}\text { Brake Pressure Front } \\
\text { [calculated] : 19.92 }\end{array}$ \\
\hline $\begin{array}{l}\text { Brake Pressure } \\
\text { [observed] : } 12.84\end{array}$ & Rear & $\begin{array}{l}\text { Brake Pressure Rear } \\
\text { [calculated] : 12.99 bar }\end{array}$ \\
\hline
\end{tabular}

After changing the bias to $55 \%$ in Front and $45 \%$ in Rear System and applying $30 \mathrm{~kg}$ force, we get,

\begin{tabular}{|l|l|}
\hline $\begin{array}{l}\text { Brake Pressure Front } \\
\text { [observed] :28.64 bar }\end{array}$ & $\begin{array}{l}\text { Brake Pressure Front } \\
\text { [calculated] : 29.88 bar }\end{array}$ \\
\hline $\begin{array}{l}\text { Brake Pressure Rear } \\
\text { [observed] : } 19.83 \text { bar }\end{array}$ & $\begin{array}{l}\text { Brake Pressure Rear } \\
\text { [calculated] : 19.49 bar }\end{array}$ \\
\hline
\end{tabular}

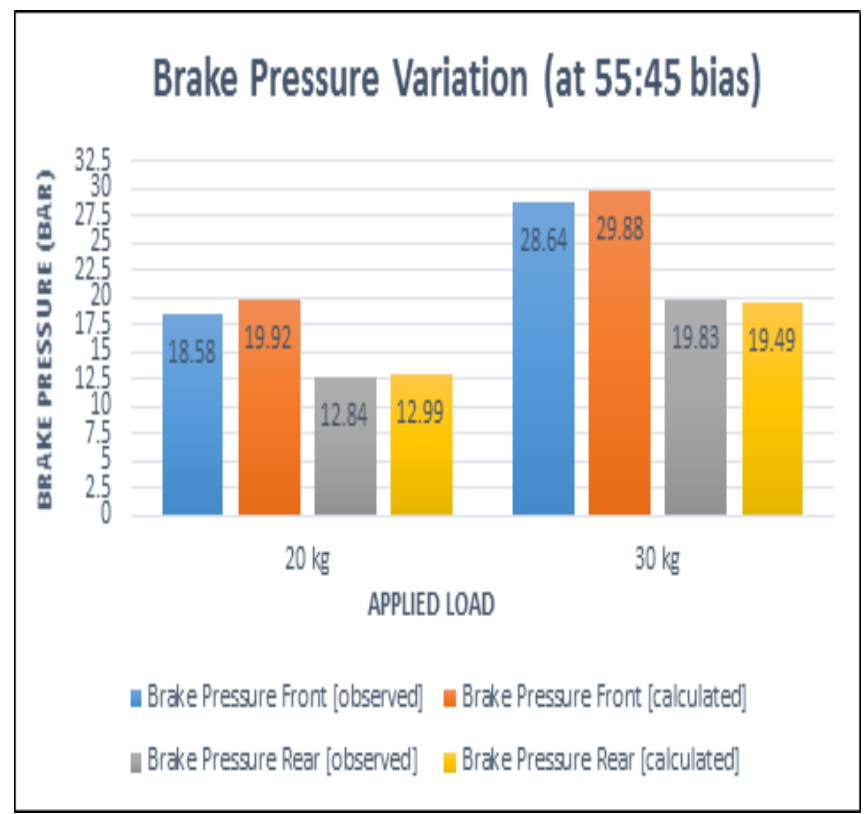

Fig -12: Summary of test performed at 55-45 bias

\section{CONCLUSION}

A lightweight assembly was designed, fabricated and tested to prove its performance and reliability. A user needs to apply a pedal force of up to $40 \mathrm{~kg}$ to achieve maximum potential of the system, which is much lesser than the average panic braking force that can be applied by the average person. This has been verified through track testing via the use of an accelerometer and two brake pressure sensors.

\section{REFERENCES}

[1]. Tune to win by Carroll Smith

[2]. Brake handbook by Fred Puhn

[3]. ASM Material Data sheet: http://asm.matweb.com/search/SpecificMaterial.asp?bassnu $\mathrm{m}=\mathrm{MQ} 410 \mathrm{BF}$

[4]. A P Racing master cylinders: https://www.apracing.com/products/race_car/master_cylind ers.aspx
[5].
ISR
Calipers
Catalogue:

http://www.isrbrakes.se/catalogue/

[6]. SAE Design and Analysis Project with SolidWorks Software:

https://www.solidworks.com/sw/docs/SAE_Project_WB_20 11_ENG.pdf

[7].

Brake

sensor: http://thesensorconnection.com/category/brake-sensors/allbrake-sensors 